Est $\mathrm{Ag} 42$ (2007) 335-363

\title{
Ortega y los Azcárate
}

\author{
Una Escuela de Valores
}

\section{1. "Don Gumersindo de Azcárate ha muerto": (Ortega y Gasset 1917)}

El escrito de Ortega a la muerte de G. de Azcárate sólo es comparable por su vibración humana y calidad literaria a los dos artículos publicados, por él mismo, en la muerte de Max Scheler y de Unamuno.

Con la muerte de G. de Azcárate, dice Ortega, entra definitivamente en la historia una edad de la vida española. Estos hombres eran como los supervivientes de una vida "más heroica, más enérgica, de mayor frenesí espiritual, sobre la cual había venido luego un diluvio de corrupción, cinismo y desesperanza"1. Al desaparecer sus mejores contemporáneos, Azcárate condensaba aún, en sí mismo, "todas las alusiones, remembranzas y sentimientos" más elevados que nos dejaba el pasado.

Para todos era consolador pensar: "¿Queda Azcárate!" "Enjuto, de aventajada estatura, barba de plata y rostro cetrino, le veíamos pasar, emocionados, como a un Don Quijote vuelto a la cordura. Con él pasaban las sombras de Castelar y Cánovas, Salmerón y Giner. Cuando entraba y salía, entraba y salía en nuestras almas una vasto rumor de ideales entusiasmos, una cálida ráfaga de esencial patriotismo y trascendente humanidad"2.

La vida cambia con cada generación, cada una trae distinta sensibilidad y distinto modo de pensar y valorar las cosas, de amar y acercarse a ciertas cuestiones y de alejarse de otras. En cada generación conviven los abuelos, los padres y los hijos. Así, convivieron los hombres de la primera

1 ORTEGa y Gasset, J., Don Gumersindo de Azcárate ha muerto. O. C. III, Madrid 1983, 11.

2 Ortega y Gaset, J., Don Gumersindo 11. 
República, los de la Restauración y la generación novísima, que era la de Ortega. Estos hombres novísimos sentían más afinidad con los hombres de la Gloriosa de 1869 que con los de la Restauración. Para Ortega, lo que les contagiaba y atraía no era tanto el nombre de la República sino "su sentido moral de la vida, su anhelo de saber y de meditar. Frente a ellos, los hombres educados en la Restauración parecían desmoralizados y frívolos, exentos de curiosidad y de estudio". Aquellos eran profesores, amigos del libro y de la idea, éstos, abogados, negociantes aficionados a la intriga.

Con Azcárate se va una casta de hombres "que creía en las cosas superiores y para los cuales toda hora llegaba con un deber y un escrúpulo en la alforja". Y como toda casta noble se aquilata en la adversidad y sutiliza las excelencias de su linaje, al transcurrir de los tiempos: "la sangre de aquella venerada generación vino a adquirir en Azcárate, su hombre último, la más pura y sencilla calidad. Muere solo, nuestro bueno y amado Don Quijote de la barba de plata, solo entre sus libros y sus virtudes"3.

Muere solo, en la soledad de los suyos, pero quedamos en el futuro, y nuestra piedad filial consistirá en seguirle. Porque seguir a Azcárate, como a Giner, es "seguir hacia delante". "De un egregio pasado español ya no queda nada: ¡Ya no queda Azcárate!”. -“Pero ahora queda sobre su tumba lo que debe quedar siempre cuando los que viven son fieles a los muertos: el verde brote de la esperanza" (El Sol 15-12-1917).

\section{Patricio de Azcárate, Sanz del Río y la Filosofía Española}

El pequeño pueblo de Villimer fue siempre una "especie de hogar espiritual de los Azcárate". Según Nicolás M. Sosa: "En 1848, buscando sin duda un lugar de veraneo para la que ya comienza a ser numerosa familia, así como paz y sosiego para sus meditaciones, don Patricio compró al Marqués de Gaztañaga una casa y algunas fincas contiguas en la aldea de Villimer. Con ello, el antiguo dueño le cedió el derecho de presentación del curato de aquel lugar. Villimer es una aldea a orillas del Porma, poseedora, como todas las riberas leonesas, del contraste entre el verdor y frondosidad de la tierra cercana al río y la sequedad adusta de la meseta. El caserón que adquirió don Patricio era de tapial y adobes y tenía detrás un gran huerto y unos prados, cercados por arboleda. El ambiente de paz y

\footnotetext{
3 Ortega y Gaset, J., Don Gumersindo 12.
} 
de intimidad lo sigue ofreciendo hoy la propiedad, perfectamente conservada. Villimer pertenece actualmente al municipio de Villasabariego, del que dista unos tres kms. y medio, y tiene una población de 167 habitantes, agrupados en 56 familias, con cierta tendencia a disminuir"4.

En esta casa, de Villimer, D. Patricio y su familia pasaban siempre los veranos, hasta primeros de octubre. En carta, a Sanz del Río, el 28.9.1864, dice P. de Azcárate, al fundador del krausismo español: "ya sabe V. lo mucho que le aprecia toda esta familia y que Villimer está siempre a su disposición". Y en otra carta, después de felicitarle, por su liderazgo filosófico, le dice que no está de acuerdo "con que se vaya V. a tierra de Cameros, cuando toda mi familia, contando con su promesa, le espera de fijo en Villimer, y tanto que hace tiempo tengo prevenido a Gumersindo que no venga sin ponerse de acuerdo con $\mathrm{V}$. para venir juntos, y precisamente pensamos salir toda la familia esta semana para aquel punto. Anímese V. y recuerde estas riberas frescas, que en estío proporcionan al alma, libre de los ardores de la estación, solaz bastante para esparcirse por el venturoso campo de la filosofía con algunas incursiones por el embrollado y alarmante de la política"5.

Los vecinos de este pequeño pueblo recuerdan a la familia Azcárate con cordialidad según nos dijo el sacerdote mayor, hoy ya fallecido, que atendía la iglesia. En esa casa escribió don Patricio sus obras y traducciones. Gumersindo de Azcárate, dice de Villimer: "Ningún otro sitio tiene para nosotros tantos recuerdos unidos a los que nos dejaron, como éste"6. En su cementerio están enterrados D. Patricio y su esposa. Salmerón, en su condolencia a Gumersindo, le decía: "Una gran satisfacción debe aliviar vuestra pena. Vuestro padre ha llenado bien su vida, y con haber sido larga ha tenido la virtud y el vigor raros de vivir para las ideas hasta sus últimos días"7.

\subsection{La familia humana, social e intelectual de D. Patricio de Azcárate}

Patricio de Azcárate es el padre de Gumersindo de Azcárate. Tuvo cargos políticos de importancia en la España de su tiempo. Amigo de Es-

\footnotetext{
${ }^{4}$ Sosa, N. M., D. Patricio de Azcárate, un leonés universal. Instituto Fray Bernardino de Sahagún de León. Universidad de Salamanca 1982, 87.

5 PABlo de AzCÁRATE, Sanz del Río (1814-1869). Apunte biográfico por F. Giner de los Ríos. Documentos, Diarios y Epistolario. Tecnos, Madrid 1969, 372-373.

6 SosA, N. M., D. Patricio de Azcárate 88.

7 SosA, N. M., D. Patricio de Azcárate 131.
} 
partero, Campoamor, Laverde y Fernando de Castro. Es uno de los fundadores de la Biblioteca Provincial de León. Según Pablo de Azcárate, Patricio tuvo una rara habilidad para saber conjugar la vida familiar, la investigación filosófica y la vida política.

Fue muy amigo de Sanz del Río al que invitaba con frecuencia a Villimer ${ }^{8}$. Cuando Sanz del Río veraneaba "en Villimer (León), en casa de don Patricio de Azcárate, con quien le ligaba la común vocación por la filosofía, impresionaba a todos su profundo amor a la Naturaleza, como les cautivaba su carácter jovial y sociable, en miedo del rigor intelectual y moral de su espíritu"9. Podemos decir que Sanz del Río y Patricio de Azcárate, dieron un impulso muy importante al pensamiento español, a mediados del siglo pasado, de modo que podría afirmarse que la iniciación de la filosofía moderna en España, a ellos se debe. Así lo da a entender J. L. Abellán en sus recientes estudios del pensamiento español.

En este sentido, D. Patricio, fue el Fundador y Director de la Biblioteca Filosófica. Tradujo 11 tomos de las obras de Platón, 10 tomos de las de Aristóteles y 5 tomos de Leibniz. Creemos que Ortega utilizó esta traducción en su Idea del principio en Leibniz. Todavía hoy se usa esta traducción, de la editorial Espasa-Calpe, como puede verse, por ejemplo, en Aristóteles, Moral, a Nicómaco. Trad. del griego de P. de Azcárate, Madrid $1972,6^{a}$ ed. En esta empresa quiso D. Patricio que participaran todos los hombres de las distintas corrientes de pensamiento español, desde Salmerón a Campoamor y Valera, desde F. de Paula Canalejas a los neocatólicos como Ortí y Lara, y se mostró disgustado porque, finalmente, no fuera así10. El universalismo leonés se muestra aquí una vez más.

Patricio de Azcárate, escribió Veladas sobre la filosofía Moderna (1853), para su hijo Gumersindo, que luego tuvo un cierto éxito, según atestiguan Fernando de Castro y G. Laverde. Y también escribió: Exposición histórico-crítica de los sistemas filosóficos modernos y Verdaderos principios de la Ciencia, 4. vols (1861-1862). En esta obra, según Juan M. Palacios (1989, 648), Patricio de Azcárate hace la "primera exposición amplia, completa y correcta de la filosofía de Kant en el ámbito de la cul-

8 Pablo de AzCÁrate, Sanz del Río (1814-1869). Pablo de Azcarate fue Diputado a Cortes por León en 1918. Trabajó en la Sociedad de Naciones. Embajador de la República en Londres. En 1948 fue llamado de nuevo por la ONU que le nombró alcalde de Jerusalén durante algún tiempo.

${ }^{9}$ Giner dE LOS RIOS, F., Apunte biográfico, en Pablo de AzCÁRATE, Sanz del Río (1814-1869), 28-29.

10 SoSA, N. M., D. Patricio de Azcárate 119. 
tura española"11. En el verano de 1880, lee D. Patricio la $H^{a}$ de la Filosofia del P. Ceferino González, y de esta reflexión sale su último escrito: $L a$ Filosofía y la Civilización moderna en España.

\section{Pero, ¿qué diablos era el Krausismo?}

Casi todos los pensadores progresistas de esta época están influidos por el pensamiento krausista. Menéndez y Pelayo hablaba del krausismo, y en concreto del de Fernando de Castro, como del mismo demonio. También hablaba de las nieblas germánicas a las que habría sucumbido el señor Sanz del Río. Pero Azorín, por ejemplo, en absoluto pensaba así. En Clásicos y Modernos, asegura Azorín que el krausismo y, en concreto, Fernando de Castro es uno de los grandes acontecimientos intelectuales del siglo XIX, como ha demostrado recientemente, en su libro, D. Máximo Carracedo. En 1854 se produce la incorporación de Sanz del Río a la Universidad. Desde entonces, el krausismo no ha sido ajeno a los acontecimientos fundamentales de la vida española. "Liberalismo y krausismo se implican mutuamente dándose el caso de que aquél alcanza en éste su máxima expresión filosófica y política" (Abellán, 1984,394)12. Según Elías Díaz: "La conexión Krausismo - liberalismo es, en verdad, incuestionable; representa en esa conyuntura la antítesis progresista del inmovilismo ultra-conservador típico del integrismo tradicional o tradicionalista" 13 . Con Julián Besteiro, Fernando de los Ríos (ministro que recalaba con frecuencia en Villimer como Marcelino Pascua) y Rodolfo Llopis, se pasa del liberalismo al "socialismo de fondo humanista". Así aparecen Institucionistas en el Partido Socialista Obrero, como afirma y demuestra $\mathrm{M}^{\mathrm{a}}$. Dolores Gómez Molleda.

En Madrid había dos cátedras de Metafísica a la vez, la de Ortí y Lara y la de Salmerón, nos informa, certeramente, J. L. Abellán ${ }^{14}$. Y dado que como se ha dicho un pueblo es su Metafísica, esto nos visualiza, adecuadamente, la dualidad y una cierta esquizofrenia española. Mientras la esco-

11 SÁNCHEZ CUERVO, A.C., Itinerarios del pensamiento español en el siglo XIX, en MACEIRAs, M., (Ed.), Pensamiento filosófico español. II ${ }^{\circ}$. Del Barroco a Nuestros días. Síntesis, Madrid 2002, 178.

12 JIMÉNEZ GARCÍA, A., El krausismo y la Institución Libre de Enseñanza. Prólogo de J. L. Abellán, Cincel, Madrid 1992, 2a, 32. En adelante KI.

${ }_{13}$ Minuta de un Testamento. Publicada y anotada por Gumersindo de Azcárate. Estudio preliminar por Elías Díaz. Ed. Cultura Popular, Barcelona 1967, 9. En adelante MT.

$14 \mathrm{KI} 17$. 
lástica y el positivismo de Cousin alentaba al partido conservador, Sanz del Río trajo a España "una filosofía mística: la de Krause. Era la que muchos españoles necesitaban e iba a reinar casi un siglo", asegura Araquistain ${ }^{15}$. El krausismo se opuso al oscurantismo, favoreció el libre examen y simpatizó con lo popular, afirma Tuñón de Lara.

En cuanto a la filosofía de Krause, nos confirma que el Ser infinito es superior a la Naturaleza y al Espíritu, y al compuesto armónico de ambos: La Humanidad ${ }^{16}$. Así la dialéctica nos lleva de la unidad a la oposición y de ésta a la armonía. El sistema de Krause se llama racionalismo armónico. Krause quiere hacer ciencia en el sistema de la ciencia.

Por proceder de Dios, la Naturaleza y el Espíritu son infinitos relativos y así se valora y defiende la Naturaleza, el cuerpo humano, y, muy en concreto, a la mujer ${ }^{17}$. Por eso, el hombre debe cuidar su cuerpo, y utilizarlo como mero instrumento sería menospreciar y profanar la imagen de Dios y olvidar la ley de armonía divina en la humanidad. Hay que respetar la dignidad del cuerpo y cuidarlo por sí mismo, por su natural bondad. En sus Diarios, afirma Sanz del Río que debemos mantener el cuerpo bien alimentado, sano y ágil, aseado y pulcro, y hemos de darle una parte de razón, a sus exigencias, para que no nos inquiete demasiado y tengamos paz para la vida del Espíritu, "así debes ser paciente y tolerante con los deseos de tu cuerpo"18.

Esta es una gran novedad filosófica, ya que en las filosofía tradicionales el cuerpo no parece existir, o si existe se le condena: Se debe huir de todo cuerpo, decía Porfirio. Julián Marías se gloría de que en su Antropología Metafísica se habla, casi por primera vez, del cuerpo y de la mujer. Poco antes había tratado el tema G. Marcel. Una de las consecuencias de esta nueva idea positiva del cuerpo es el interés por la higiene que podemos aún constatar en esa misma casa de los Azcárate en Villimer: cuartos de baño, amor al campo, cultivo de la naturaleza, etc.

El krausismo para Tiberghien es la reforma más decisiva del pensamiento desde la aparición del Cristianismo y el Renacimiento, y Krause sería la culminación del gran idealismo alemán al que corona prácticamente ${ }^{19}$. Sanz del Río considera este sistema el más útil para nuestro país, dado que Hegel había caído mucho y la obra de Schelling no era conocida ${ }^{20}$.

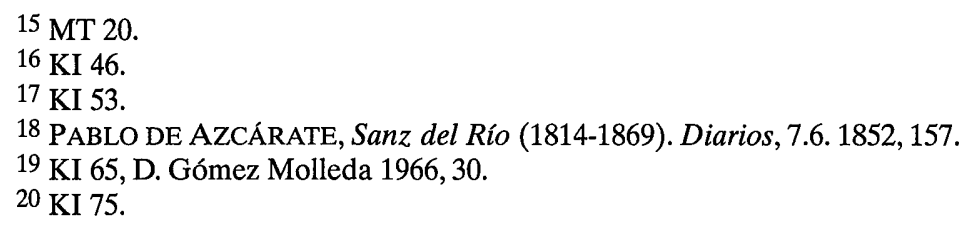


La Metafísica de Sanz del Río no es muy influyente pero sí su Ideal de la Humanidad para la vida, que no es, para muchos, ni mera traducción ni obra original. Según E. Menéndez Ureña es una simple traducción de una obra de Krause. La Humanidad es aquel ser uno, todo y propio, en el que intiman Naturaleza y Espíritu bajo la unidad de Dios. Los Mandamientos de la Humanidad fue la parte más influyente de esa obra. Estos imperativos orientadores se refieren a Dios, a uno mismo, a los demás, a ser bueno, justo y verdadero, a buscar la armonía y el bien por sí mismo y ser dócil a Dios ${ }^{21}$.

Además, se debe mirar por todos los seres, especialmente por la familia humana y la mujer. Esta es también una gran novedad, dado el extremado patriarcalismo y el machismo que ha padecido la mujer en nuestra cultura. Ortega promoverá a la mujer en la Universidad como ocurre en el caso de María Zambrano. Y este ambiente se respira en todo el grupo.

Por lo demás, al ser humano se le pide que sea sencillo, sin vanidad. Que sea un ser social, que renuncie al mal y al error. Que sea veraz, honrado y trabajador, esforzado y perseverante. Estos serían los tiempos de la tercera edad o edad armónica del mundo, plenitud humana de la historia, basada en la felicidad y perfección humana desde la libertad22. Así, más que enseñar filosofía, el krausismo enseñaba a filosofar, a pensar y a vivir. Algunas claves decisivas del krausismo son: "Espíritu de armonía, defensa de la libertad, culto a la ciencia, afirmación de la razón, moralismo, pedagogía y religiosidad"23.

Gumersindo de Azcárate pertenece a "la promoción krausista por excelencia" que, centrada en torno a Giner de los Ríos, va a hacer más perdurable el espíritu y la obra del maestro. Frente al positivismo y al idealismo que se disputaban la orientación de la vida española, G. de Azcárate, que es clave para conocer los debates en el Ateneo de Madrid, se inclina por el positivismo que tenga en cuenta el neokantismo ${ }^{24}$. Como luego hará Ortega, Azcárate rechaza, decididamente, la postura anti-religiosa y antimetafísica del positivismo: " $₫$ Puede ocultarse a nadie la gravedad del peligro que para la civilización entraña una doctrina cuyo programa se resume en esta frase: guerra a la religión y a la metafisica? Este es, sin duda alguna, el mal mayor, y el que los resume y comprende todos, que puede producir

\footnotetext{
${ }^{21} \mathrm{KI} 90$.

22 KI 93.

23 MT 19.

${ }^{24} \mathrm{KI} 116$.
} 
el positivismo moderno: Estudios filosóficos y políticos, Madrid, Victoriano Suárez 1877,120"25. Por otra parte, el mismo Azcárate reivindica la emancipación científica de España frente al "fanatismo religioso" y el "despotismo político"26.

Para el pensador Sanz del Río y el gran pedagogo Giner, resolver el problema de la educación era resolver el problema de España. En 1876, los profesores expulsados de la Universidad impulsan la Institución Libre de Enseñanza. Quieren romper con la tibetanización (aislamiento total empecinado y a sabiendas) de España en la ciencia y la enseñanza y crear un hombre nuevo, un hombre interior (Giner) sabiendo que la democratización del país depende de la educación ${ }^{27}$.

En el pensamiento pedagógico de Giner, influyen Comenio y Pestalozzi, y sobre todos F. Fröbel (1782-1852), muy identificado con Krause 28. Se trata de una educación que no es sólo instrucción sino que es activa, integral, en libertad, laica-neutral, unificada, mixta y complementaria a la familia29. F. de Paula Canalejas defiende el krausismo, contra Ramón de Campoamor que le acusa de panteísmo, y cree que la doctrina de Krause fortalece y vivifica la enseñanza cristiana que no quiere ni dualismo ni panteísmo ${ }^{30}$.

Según A. Jiménez: "El krausismo, tanto por su amplitud como por su profundidad, es el movimiento filosófico más importante de la España contemporánea. Pero no fue el krausismo sólo una filosofía; en realidad eso es lo menos que fue, sino todo un movimiento social y reformista que colaboró, en gran medida, en la tarea de transformación y modernización de las estructuras arcaicas de la sociedad española. De aquí su éxito y también su frecuente polémica con el tradicionalismo imperante. Los krausistas fueron, utilizando expresiones de Jobit y Gómez Molleda, los educadores y reformadores de la España contemporánea" 31 .

Resumiendo a Sanz del Río, Canalejas dice que el krausismo: $1^{\circ}$. En filosofía, postula el racionalismo y la libertad científica. $2^{\circ}$. En moral, propone: "Obrar el bien por el bien" $32.3^{\circ}$. En política, el filósofo respeta la constitución positiva de su pueblo que defiende las libertades frente a la

\footnotetext{
25 SÁNCHEZ CUERVO, A. C., Itinerarios del pensamiento español en el siglo XIX, 175.

26 SÁNCHEZ CUERVO, A. C., Itinerarios del pensamiento español en el siglo XIX, 180 .

27 KI 149. Subrayado nuestro.

28 KI 151.

29 KI 152-158.

30 KI 175-176.

31 KI 187. Subrayado nuestro.

32 KI 187.
} 
violencia y el poder arbitrario. $4^{\circ}$. En lo social, busca el progreso en todo y para todos. Se distancia del comunismo que no deja libertad y del individualismo que no admite ley superior alguna. $5^{\circ}$. En historia, se respeta la verdad de los hechos y las tradiciones como fuente de enseñanza pero sin que anulen el presente ni el futuro. Se trata pues de un racionalismo en lo filosófico, de un liberalismo en lo político y de un reformismo en lo social ${ }^{33}$.

"Heredera del krausismo, la Institución Libre de Enseñanza hará de la educación el móvil de la transformación radical del país, pero una educación integral y auténtica, no la mera instrucción que acumula conocimientos sin reflexión; una educación pensada por y para la libertad y la democracia; una educación concebida para hacer posible la convivencia nacional a partir de la tolerancia, lejos de cualquier sectarismo religioso o bandería política; una educación, en fin, que permita la creación de un hombre nuevo"34.

De la ILE surgen algunas grandes instituciones de cambio como la Junta de Ampliación de Estudios (ciencia), la Residencia de Estudiantes (universidad), El Instituto-Escuela (enseñanza general) y el Instituto de Reformas Sociales (agricultura). Gumersindo de Azcárate presidirá el Instituto de Reformas Sociales (1903) ${ }^{35}$.

Por otra parte, según Giner, en España, ocurre con frecuencia "que los amigos del catolicismo son enemigos de la libertad, y que los amigos de la libertad son enemigos del catolicismo"36. En tal situación, el hombre de bien defenderá ambas cosas, tanto el valor de la religión como sus convicciones políticas. Según E. Díaz, la $3^{\mathrm{a}}$ promoción de la ILE; integrada por personajes como Azaña, Ortega, Marañón y Juan Ramón J., encarna la España liberal frente a la integrista y tradicionalista ${ }^{37}$.

En resumen, el Krausismo es el Racionalismo Armónico. Racionalis$m o$ porque defiende la razón como único principio de conocimiento científico, y Armónico porque establece una síntesis superadora de las tendencias opuestas con una religiosidad racional que fundamenta la libertad religiosa. En política, y en lo social, se declara liberal por antonomasia y rechaza toda injusticia, violencia o arbitrariedad.

Se trata, todavía, de una concepción organicista de la sociedad entre individuos y grupos que permita a todos cumplir felizmente su destino

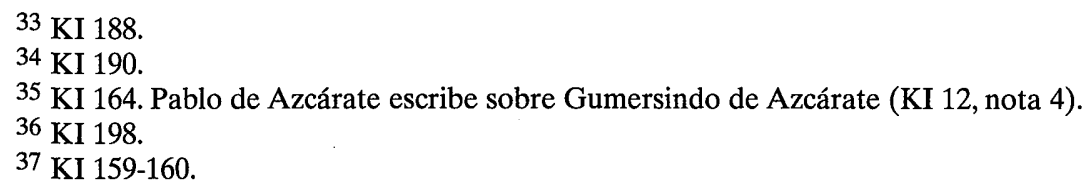


humano. Defiende una reforma constante y progresiva que lleve a la transformación de las personas y los organismos sociales para la plena realización del ideal humano en la historia. Y confía en la educación de la persona, como el camino más seguro, "para lograr la reforma individual y social"38.

Por lo demás, el krausismo, a pesar de las durísimas descalificaciones de Menéndez y Pelayo, ha sido reconocido ya por casi todos los pensadores del problema de España, desde Unamuno a R. Ledesma Ramos, como un movimiento social y de pensamiento importantísimo para España, como ha demostrado, fehacientemente, el profesor Roberto Albares ${ }^{39}$.

\section{La Minuta de un Testamento, de Gumersindo de Azcárate}

Este escrito apareció en 1876, a raíz de la renuncia de G. de Azcárate a su cátedra, publicado y anotado por W. Ahora bien, desde el primer momento se entendió que el autor del texto era G. Azcárate, expulsado de la Universidad y confinado en Cáceres como Salmerón en Lugo o Giner en Cádiz, y uno de los fundadores de la ILE ${ }^{40}$.

Gumersido de Azcárate fue un liberal puro, defensor a ultranza del sistema Parlamentario y del sistema de Partidos 41 . Hombre de gran vocación Universitaria, albacea de Sanz del Río, fue simpatizante de la revolución de 1868 y a la que colabora activamente, desde una Dirección General al Ministerio de Gracia y Justicia, con Salmerón.

Parlamentario nacional por León durante muchísimos años, casi 40 años. Lo único decente que le quedaba, al fin, al sistema Parlamentario, en palabras de Unamuno, como nos recuerda muy bien el profesor Marcos Oteruelo. Siempre contra toda violencia y enemigo de toda precipitación revolucionaria, no estaría lejos de un neo-socialismo humanista como no lo estuvo Ortega.

Según Araquistain, G. de Azcárate llevó el armonicismo krausista al Instituto de Reformas Sociales. En la última época de su vida, colabora con su amigo Melquíades Álvarez, fundador del Partido Reformista, en 1912. Ahí se encuentra también con Ortega, Azaña, Américo Castro, Adolfo Posada y otros.

38 Albares, R., Juliân Sanz del Río y el Krausismo, en M. Fartos, L. Velázquez, T. Pastor, La Filosofía Española en Castilla y León, Universidad de Valladolid 2000, 274.

39 AlbARES, R., Julián Sanz del Río y el Krausismo, 237-238.

40 MT, Cultura Popular Barcelona 1967.

41 MT 41. 
“La Minuta de un testamento, autobiografía de Azcárate, ligeramente transformada, es, dice Cacho Viu, la obra más importante que entonces publicaron los krausistas; viene a ser-escribe María Dolores Gómez Molleda- una especie de manual del perfecto krausista. Puede decirse -había señalado, en efecto, Jobit- que es la actitud del krausista medio la que Azcárate fija en su preciosa Minuta"42.

Según López Morillas se trata de vindicar al autor y a sus correligionarios y de ofrecer una exposición breve y sencilla de la vida krausista. Además, se compatibiliza, perfectamente, la religión con la libertad, el catolicismo con la civilización moderna, y, como ha escrito muy bien Jiménez Lozano, nunca mostraron los krausistas odio alguno a la religión ni al catolicismo ni a la Iglesia católica, cosa que también heredó Ortega.

Aquí trataremos de presentar algunos temas más fundamentales, a partir del hecho de que el testamento ha venido a las manos del autor por "rara casualidad", tan "rara" que era su propio testamento.

\subsection{Primeros pasos en la vida hasta llegar al matrimonio}

Dice el autor del Testamento que va a dar un resumen de su vida, con sus merecimientos y fracasos, incluida su postura religiosa, para legarla a la familia y al juicio de la posteridad, pues, como decía Séneca, el legado de la vida es el más importante. Además hace una distribución de bienes, tanto a su familia como a sus amigos, a su pueblo y a la humanidad porque homo sum et nihil humani a me alienum puto ${ }^{43}$, según decía san Agustín con palabras de Terencio: soy hombre y nada humano me es ajeno. También va a dar unos consejos razonados y unas recomendaciones a sus hijos. Así, cumple, el testamentario, un sagrado deber de conciencia y de vida.

$\mathrm{El}$ autor es hijo de un profesional partidario del movimiento "científico y religioso" que inauguró el siglo XIX y que, bajo las ideas de la Ilustración, había abandonado sus convicciones religiosas en favor de los grandes ideales modernos. A su madre, muy religiosa, le inspiraba la caridad hacia los desgraciados y pequeños, pero no siempre la idea de igualdad que embargaba al autor del Testamento. De su madre recibe la educación religiosa pero nunca oyó a su padre duda alguna ni menosprecio a la religión. La enseñanza moral la recibe del ejemplo del hogar.

42 MT 72.
43 MT 87. 
La educación le toca recibirla en el tiempo de la letra con sangre entra, de la que no sufre sus consecuencias, pero sí el estímulo del amor propio en la educación que crea enormes rivalidades. Las Humanidades, entonces, se reducían al latín y no se estimulaban ni despertaban las cualidades propias del individuo, para su mejor desarrollo, sino que simplemente se instruía a la persona. Así, Gumersindo, comienza a sentir simpatía por ciertas asignaturas y por los profesores más dedicados. Al terminar sus estudios no siente gran alegría. Y se da cuenta, también, que no basta tener un buena profesión sino que se precisa vocación ${ }^{44}$. El materialismo científico no le afecta pero sí el problema de las ciencias naturales y las creencias religiosas, en relación con el tema del origen del mundo. Finalmente, nuestro testamentario, se hace Profesor, una meta importante para él.

Con todo, el autor, estima que "la mayor dicha de mi vida y por la que más gratitud debo a Dios, (es) el haber conocido a la que ha sido y es dulce y cariñosa compañera de mi vida, y con la que he realizado el consortium omnis vitae del jurisconsulto romano"45. Aquí aparece, con claridad, la importancia de la mujer y la familia, que el krausismo reivindicó siempre, fundado en el valor de la persona, su educación, los valores morales y el amor familiar.

\subsection{El problema religioso, la familia y la sociedad}

Sin embargo, nuestro autor nos confiesa que no ha tratado con su mujer el problema religioso. El autor admite la creencia en Dios y respeta el cristianismo pero rechaza a los fanáticos sin caridad y a los volterianos sin luz ni ciencia. Contrae matrimonio en medio de una cierta crisis de fe pero se siente feliz en su nuevo hogar, y en esa familia "íntima, santa y natural", muy celebrada por Paul Janet en La Famille.

La religión, en la que cree el autor, informa toda su vida. Se trata de un Dios personal y providente, íntimamente unido a la vida, que da la inmortalidad y cuya providencia amorosa alcanza a toda la historia. Su manifestación más alta es la vida cristiana que ofrece al hombre un Ser absoluto e infinito, la vida de Jesús como ideal práctico y regla de una vida moral "pura y desinteresada, como ley social el amor y la caridad, como dogma el Sermón de la Montaña, como culto la oración dominical"46.

\footnotetext{
44 MT 103, nota 20.

45 MT 108-9.

46 MT 118.
} 
Se trata del cristianismo liberal, parecido al de Lacordaire y de Gratry, no del Credo tradicional, anota el albacea del Testamento, que teme crear una crisis a su esposa, si le revela su situación, pero también juzga imposible ocultarle su intimidad por lo que se decide a hablarle. Así, le presenta algunas grandes personalidades humanas de otras religiones, $y$ le expone la importancia de la sinceridad y de la asimilación personal de la religión en base a razones auténticas.

Aprovecha la ocasión de la apostasía de un sacerdote, de la que da cuenta la prensa, que unos presentan como un horrible renegado y otros como pura coherencia de conciencia, para exponer su situación religiosa a su mujer. Hace ver a su mujer cómo la Iglesia que recibe al converso, le llama convertido y la que lo pierde apóstata. Según nuestro testamentario, la persona que obra en conciencia es un convertido y el que actúa sin conciencia apóstata de sí mismo y, por tanto, de la religión. Pero la gente suele llamar apóstata al que es sincero e hipócrita al hombre honesto y coherente. En fin, hay que odiar los errores y amar a los hombres, como dice san Agustín, y esto vale especialmente para los amigos, los hijos y al compañero de hogar, le dice su esposa, que le emociona, con un amor cristiano propio del Sermón de la Montaña y de la parábola del Buen Samarita$n o^{47}$.

El testamentario siempre ha sido muy respetuoso con las creencias de los demás, especialmente en su cátedra, y siempre ha subrayado lo que une a los creyentes. Piensa que aunque hay diferentes creencias también puede unir mucho la coincidencia en una conducta moral honesta y una feliz y respetuosa armonía. El autor no desea para su hijos un catolicismo frío y dogmático, con más odio que amor y más dado a la guerra que a la paz. La familia originaria se reunía para la oración, la lectura del evangelio y libros piadosos, pero el autor dice que no asistirá, en adelante, ni al rosario ni a las novenas por la confusión que existe en el culto a los santos y la recitación rutinaria, mecánica y tibetana de la oración de los cristianos ${ }^{48}$.

Según G. de Azcárate, para muchos la religión es cosa de mujeres, niños y moribundos e, incluso, está bien visto ser católico aunque no se sea practicante. Ortega solía decir que los españoles somos buenos creyentes pero malos parroquianos. Nuestro autor defiende que la más santa de las libertades es "la libertad de conciencia y de cultos" y asume el cristianismo de los unitarios predicado por Channing; de ahí que asistirá a la igle-

47 MT 128.

48 MT 140-1. 
sia pero no a la misa. A sus amigos les dará explicaciones adecuadas de su conducta.

Por lo demás, creía en la inmortalidad del alma y quería ser enterrado junto a su mujer pero "sin mengua de la integridad de nuestra conciencia". Y como hay cementerio civil y católico, el autor quiere respetar los ritos y ceremonias adecuados tanto vivo como muerto. Ciertamente a él, le repugna que sus huesos vayan a parar al cementerio civil, "pero más me repugna que vayan al otro si para ello he de morir mintiendo; y así, si continúan las cosas en el mismo estado, es mi voluntad que me entierren en el cementerio civil, poniendo sobre mi sepulcro una cruz y esta inscripción: Amaos los unos a los otros"49. Todo esto lo dispone así, nuestro testamentario, porque ya existía el precedente del maestro Sanz del Río.

\subsection{La intervención en la política}

Varias causas contribuyen a su participación en la política y a que profesara ideas de orientación liberal. En primer lugar, esas eran las ideas de su padre y las enseñanzas recibidas en la Universidad. Además le repugnaba, por su propio carácter, el absolutismo. Le encantaba la altivez y la independencia española cuando sentenciaba: rex eris, si recta facis; autem si non facis, non eris, según decían los concilios de Toledo y el juramento de los Reyes de Aragón ${ }^{50}$. Le encantaba la libertad de los Comuneros así como los pronunciamientos para establecer los principios constitucionales de comienzos del siglo pasado. Pero hoy cree que nuestra altivez española ha degenerado en indisciplina, le encanta la revolución pero detesta las parodias de dictaduras, motines y golpes de estado que sólo satisfacen pasiones bajas y mezquinas.

La ilustración universitaria era liberal pero solía ser anti-religiosa. Nuestro autor cree que se puede ser "católico y liberal" y se identifica con el catolicismo liberal que reinaba en Francia y Bélgica, y creía que "podía todavía el catolicismo servir en gran manera a la causa de la civilización"51. Estas eran también las ideas de Fernando de Castro como se puede ver en su Sermón a Castellanos y Leoneses, de Mayorga de Campos. Eso mismo hicieron los discípulos de Ortega. Siente, nuestro autor, que el Syllabus parece haber declarado incompatible el catolicismo con la

\footnotetext{
49 MT 151.

$50 \mathrm{MT} 154$.

51 MT 157.
} 
civilización moderna, pero hoy hemos visto cómo el Papa Juan Pablo II, dijo todo lo contrario, en Madrid, no hace tanto tiempo.

$\mathrm{El}$ autor defendió el sistema constitucional con la pluma y con las armas. Sabe, por experiencia, que una "guerra civil es horrible", pero él mismo, que pasaba por ser muy humano, aplaudió o disculpó hechos injustificables. En la guerra se cree que todo vale, que el fin justifica los medios, y se olvida la justicia, el derecho y la moral. En el mundo liberal, nuestro autor, se afilió al partido progresista que hizo la reforma constitucional moderna. Le costaba la disciplina de partido y, entre sus correligionarios, tomó fama de díscolo, pero ante su conciencia era muy disciplinado.

En las elecciones nunca hizo lo que llamaban atrocidades pero sí usó la así llamada influencia moral. Ambas cosas las considera, hoy, un verdadero crimen, pues la corrupción electoral lleva a la corrupción parlamentaria y administrativa, motiva las revoluciones y los pronunciamientos, desprestigia el sistema y reaviva las esperanzas insensatas de los del antiguo régimen ${ }^{52}$. Nuestro testamentario ha sido conspirador, como todos los liberales, aunque eso le paralizara mucho o le helara la sangre. Tomó parte en la Revolución de 1868 y no se arrepiente, aunque le repugna todo recurso a la fuerza, cree que el pueblo tiene ese derecho frente a la tiranía. Le repugna el movimiento cantonal y los actos de pura fuerza. Pero no es pesimista, y acepta la Monarquía, si beneficia al pueblo y hace las reformas que conducen al bien común.

\subsection{Enseñanza y educación}

La profesión que uno ejerce es lo que más le une a la sociedad. Lo más importante de la profesión no es lo que uno gana, con ella, económicamente, sino la vocación que uno ejerce al seguir su propia "voz interior". Esta es una idea muy desarrollada por Ortega, especialmente en los escritos sobre Goethe. Ahora bien, nuestro autor tiene que reconocer que el educador no siempre actúa por un móvil puro y desinteresado, pues también interviene el amor propio: "en fin, aspiraba a la fama y soñaba con la gloria" 53 . Pero finalmente, triunfa el amor a la ciencia y a la propia misión en la sociedad que es como un ministerio sagrado, un sacramento de difícil administración, decía Ortega, que no se pueda utilizar para fines personales.

\footnotetext{
52 MT 161.

53 MT 168.
} 
Ahora bien, la educación, además de instrucción, es formación. El profesor es a la vez educador de la juventud, sobre todo con su ejemplo, y este se ofrece, especialmente, cuando se hace comprender, con el propio testimonio, la "santidad del trabajo", cuando se valora justamente a los alumnos en sus ejercicios académicos y se estimula la colaboración de todos a la "obra común". A veces el profesorado carece del sentido de su misión y cae en la inercia y la rutina.

G. de Azcárate explica que cuando la dignidad de algunos compañeros profesores se ha visto hollada "he hecho dimisión de mi cátedra" 54 . El autor no quiere que haya otra lucha, en la Universidad, que la de la verdad con el error, desde la paz y el respeto mutuo de todas los sistemas y escuelas.

\subsection{La familia y los hijos, su educación y profesión}

El autor, considera la educación de los hijos como uno de los deberes más delicados de la vida. Ha procurado darles ejemplo de trabajo y de virtud, de buenas costumbres y sanas amistades. Y como no quiere justificar la inmoralidad como exigencia de la naturaleza, ha procurado darles una buena educación sexual. Así valora muy positivamente el matrimonio y la familia que ha decaído tanto en nuestros días. La familia es vivir en otro y vivir para otro y eso requiere abnegación y sacrificio. Lo importante no es el linaje sino la educación. Además, no se debe valorar el dinero sobre todas las cosas, como hoy es común, porque entonces el matrimonio puede convertirse en una "venta infame", y así se lo ha trasmitido a su hija.

Después de la educación de los hijos también es importante la profesión o la carrera y la preparación de los estudios. El autor ha procurado conocer y descubrir las cualidades de sus hijos "a fin de conocer su verdadera vocación" y guiarles sin coacción alguna ${ }^{55}$. Uno de los hijos se inclinaba más a la filosofía y cuestiones morales y el otro a la utilidad de la industria. El primero se orientó fácilmente en sus estudios.

El segundo quiso ser militar pero el padre no veía cómo puede haber una vocación que "consiste en matar y destruir", y al hijo se le pasó. Por

54 MT 173. Se trata de la segunda cuestión universitaria que afecta a Giner y a Salmerón y al mismo Azcárate. La primera afecta también a Sanz del Río y a Fernando de Castro.

55 MT 183. 
otra parte, el ser industrial le parecía quedarse sin carrera. Se trata de un error gravísimo, muy común en España, y origen de muchos de nuestros males. El autor hace ver a su hijo que lo importante es la vocación y la propia realización. Al fin, acepta ser Ingeniero industrial y compatibiliza todo. Los dos hijos se trasladan a Madrid donde, según nuestro autor, se reúne algo de todo "lo bueno y todo lo malo de España".

Por entonces, surge en la prensa la polémica de los textos vivos. Se trata de la famosa polémica de los tradicionalistas o neocatólicos contra los profesores krausistas. Es un asunto muy triste y la famosa frase es muy curiosa porque es de santa Teresa. Ahora bien, no basta con alejar los peligros, como creen los educadores del antiguo régimen, hay que formar para vivir en libertad y confrontar adecuadamente la fe y la razón, huir del sectarismo y actuar con una integridad que, a veces, falta, también entre los profesionales del derecho, desde sus primeros trabajos.

\subsection{Los bienes de la fortuna}

El testamentario recibió sus bienes de sus padres, y los acrecentó con su esfuerzo y economía. Cree que la economía no debe regirse sólo por el interés individual y el egoísmo y que debe estar sujeta a unos principios morales. Esta ha sido una gran tradición familiar y social de los Azcárate, asegura una persona ajena a la familia, D. Alejandro Valderas. Frente a las utopías, sin sentido práctico, y el individualismo dogmático, de la propiedad privada, hay que analizar los actuales problemas sociales, tener en cuenta la realidad concreta, y la sensatez necesaria como hace ya hoy el neo-socialismo 56 .

Por otra parte, ahora, no basta trasmitir una riqueza económica a los hijos. Hay bienes más importantes que el dinero, y, además de la familia, también están los deberes de la amistad, la cultura, la patria y la humanidad. Como a veces, estos deberes, no están del todo reconocidos, jurídicamente, ruega a sus herederos que respeten su testamento y resuelvan pacíficamente todo posible litigio.

Y, así, nuestro ilustre Testamentario dispone: En primer lugar, a su "querida mujer, la inseparable compañera de mi vida; y en recuerdo de la completa felicidad que yo he gozado a su lado, la lego todos mis muebles, alhajas, enseres y ropas, a fin de que quede intacto el hogar, testigo de

56 MT 193. 
nuestra dicha"57. A ella deja también todo el dinero que tenga en el momento de fallecer como justa recompensa en la conservación y acrecentamiento de sus bienes y los que ella aportó. Deja a su hijo mayor el reloj que él heredó de su padre que simboliza el tiempo bien aprovechado. Deja a su hijo menor el anillo de boda para que le sirva a él, también, para un feliz matrimonio.

A su hija le deja el cuadro del dormitorio que tiene pintada la cruz de Cristo con la inscripción que resume su santa doctrina: amaos los unos a los otros. Lega a un amigo católico las Obras del ilustre Channing. Deja a su amigo C., el instrumental de cirugía, de un antiguo compañero, que supo hacer justicia a sus convicciones, y que tiene con él, en común, el principio de la lógica de Malebranche: "ser hombre honrado".

Deja también a la viuda, de su fiel servidor durante años, una pensión vitalicia de tres reales diarios, y su vivienda actual, que heredarán sus hijos menores si ella falleciese. También deja dos mil reales al primero de sus criados y mil al segundo. A un pariente le deja dinero para pagar la carrera de su hijo. Al Hospital del pueblo, en que nació y se crió, le deja 70 mil reales, para ancianos incurables que no tengan hijos. Al Hospicio del pueblo en que vive le deja 40 mil reales para mejorar sus condiciones higiénicas.

Deja a la Provincia de (León)... 80 mil reales para fomentar la $E s$ cuela de artes y oficios. Este es un tema que el krausismo, cree de interés nacional para conseguir una mayor unión entre ciencia, industria y comercio, como se ha visto más arriba. A la Nación le deja 20 mil reales para premiar la mejores Memorias sobre establecimientos penitenciarios. Es un tema que Azcárate trabajó mucho, como parlamentario, de acuerdo con la ideas de Concepción Arenal. Deja también 20 mil reales a la Asociación para el progreso del Derecho Internacional.

Lega también 80 mil reales a la Iglesia católica y anglicana, a partes iguales, para las misiones que ambas tienen en Asia, África y Oceanía, para contribuir a la difusión del cristianismo y ayudar a los que así llevan la cultura a todos los pueblos. A la Universidad le deja todos los libros de su especialidad. También lega 40 mil reales a la facultad de Medicina para premiar las mejores Memorias de Fisiología e Histología. Deja a la Facultad de Filosofía y Letras 40 mil reales para premiar Memorias sobre Filosofia e Historia de la Religión. Así, el testamentario ha tenido en cuenta a todos: mujer, hijos, parientes, criados, amigos, pueblo, Provincia, Nación, Humanidad, Ciencia y Religión, así como el destino universal de los bienes ${ }^{58}$. 
El reparto de los bienes no lo hace en porciones exactamente iguales, sino para que cumplan su fin económico, en interés de la sociedad y de sus propios hijos. Al hijo mayor le deja las fincas urbanas y rústicas que heredó de su padre y la casa en que vive, salvo el derecho de habitación que concede a su querida esposa.

Recomienda a su hijo que respete a todos los colonos que durante largo tiempo vienen labrando la fincas rústicas, y conceda a tres de ellos un canon moderado para que las tres huertas que labran, desde hace más de 20 años, sean un día de su exclusiva propiedad. Que tenga buenas relaciones con todos los colonos y proteja a los débiles, y atienda y auxilie a los vecinos del pueblo, "donde tengo mi modesta casa de campo, los atienda y auxilie en la medida de sus fuerzas" 59 , siendo generoso con ellos en los años de malas cosechas, para que reine la armonía entre todas las clases sociales. Así, el testamentario reconoce el problema social y tiene en cuenta la Fía. del Derecho de Ahrens al respecto.

Al segundo hijo, le hace heredero de la mina de plomo y la fábrica a ella unida. Le recomienda el sistema de salarios y participación en la empresa, y la atención a los obreros, en sus reveses de fortuna y en su educación humana, moral y religiosa. Nuestro autor cree que no hay que caer en el error de una mísera justicia legal.

En cuanto a su hija le deja todos los valores que posee en títulos de Deuda pública. Pero no desea que sus herederos jueguen a la Bolsa con ellos sino que los usen, adecuadamente, sin convertirse en jugadores. De nuevo se recuerda el sentido social y responsable de la utilización de los bienes promovido por los Azcárate.

\section{7. Últimos consejos a los hijos}

Finalmente, va a dar algunos consejos a sus hijos que espera contribuyan a su felicidad. No se trata de mantenerles en una tutela ilimitada sino de "decirles mi última palabra". No intenta ahora recordar los principios morales consabidos sino "ciertos vicios" que son comunes en nuestra sociedad y que pasan inadvertidos y al final arruinan toda moral y dejan a ésta reducida al puro Código penal. Además, se trata de avisar, a sus hijos, sobre su carácter y posición social para que no se enamoren de sus propios defectos. Mientras viva su madre no habrá problema, pues su

${ }^{59}$ MT 215. 
vida será un recordatorio moral perfecto, pero luego conviene que quede constancia.

Uno de los problemas actuales es la crisis de valores morales y religiosos, con una religión rutinaria o del miedo y un culto muy externo, o un misticismo vago sin incidencia vital alguna. La ciencia, que nos ha dado tantas cosas, no ha creado aún "nuevos principios que puedan servir de guía a la humanidad"60. La filosofía aún comparte hoy con la religión la cura de almas, pero a la moralidad actual le falta vigor. La consecuencia es que, en la religión, la hipocresía es muy frecuente y poca la sinceridad y valentía en las convicciones.

En la economía predomina el egoísmo individual. El interés es un móvil legítimo pero necesita sentido moral y humano. En política, la decadencia moral es mucho mayor, el egoísmo predomina, se sacrifica la razón y la patria al partido. La impaciencia por el poder cunde, y el autor pide a sus hijos que tengan siempre presente la conducta que observó su padre, "en los últimos años de su vida", para no someter nunca los principios sagrados y la patria a los intereses partidistas. No se puede parlamentar entre el bien y el mal, y no se debe disfrazar el miedo de prudencia.

El hijo mayor, con su carácter bilioso, es decidido en su sentido moral, pero puede ser demasiado duro con los extraños aunque sea muy cariñoso con los que ama. El hijo menor, por su profesión mercantil puede inclinarse a una "excesiva tolerancia", más peligrosa que la acritud de su hermano. No es buena la simpatía y amistad con quien no respeta la moral porque no le ayuda a él a mejorar y alimenta, poco a poco, la inmoralidad de los demás. La excesiva dureza puede también dar la impresión de que la virtud es cosa "difícil, seca y antipática"61.

El hijo mayor mira con demasiado respeto el matrimonio. Pero no hay que dejarse llevar por excesivos temores y preocupaciones o por las dudas de la propia capacidad para la vida del hogar. Además, también hay que confiar en la providencia, especialmente en este tema de la formación del hogar. El hijo menor permanece soltero porque no quiere renunciar a la libertad que perdería con el matrimonio. Desconoce los puros y nuevos goces de la familia y su vida social. El padre teme también que así vea a la mujer como un mero instrumento de los goces efímeros y del galanteo insustancial. 
En cuanto a su profesión, aconseja a su hijo menor que no se deje llevar por las maravillas alucinantes de los negocios pasajeros, que ha producido el desarrollo del crédito, sino que proceda con discreción.

En cuanto a su hija le aconseja que no se encierre en un dogmatismo religioso, "estrecho e intolerante", que puede perjudicar la paz y felicidad de su hogar y amortiguar el sentido de la caridad cristiana que es fuente inagotable de amor y de benevolencia con todos, especialmente, con los suyos. Además debe unir la religión con la ciencia porque la cultura no es un adorno para la mujer sino una necesidad para poder ayudar sabiamente a los suyos.

Termina nuestro autor: Este testamento lo escribe con los ojos puestos en Dios y atendiendo la voz de la conciencia. Ha procurado ser sincero en la reseña de su vida, justo en la distribución de sus bienes, y prudente y discreto en dictar consejos a sus hijos. Que le perdonen si no ha acertado y miren la buena intención que le guiaba. Ha mostrado respeto a la religión, valoración positiva de la vida cristiana y su renovación, para el bien de los pueblos, como hizo también Fernando de Castro.

Ha reconocido la cuestión social como también lo hizo Le Play. Condena el espíritu revolucionario como estado de guerra permanente. Su distribución de los bienes demuestra que "sólo posee un alma libre aquel que obedece siempre libremente la ley de Dios; que obra, es verdad, como quiere, pero que quiere siempre lo que debe" 62 . En cuanto a la cuestión política se opone al partidismo y pide imparcialidad para resolver los conflictos del presente. Hay que armonizar tradición y progreso.

\subsection{La Religión y las religiones}

Se trata de una conferencia pronunciada el 16-5-1909 en la Asociación El Sitio de Bilbao. En ella dará Ortega su famosa conferencia sobre Vieja y Nueva Política en 1914. Comienza diciendo que él no cree que "el liberalismo sea pecado". Pero no deja de ser curioso que haya una edición hasta en 5 ó 6 idiomas de la famosa obra de Sardá y Salvany, El liberalismo es pecado. No obstante, no va a tratar aquí del clericalismo ni de cuestiones políticas o de derechos como la libertad de conciencia, el matrimonio civil, los cementerios, etc., aunque alguien ha dicho que "los católicos militantes en España no eran más que un partido político".

62 MT 251. 
Los extremistas españoles creen que sólo hay una religión verdadera, dice Azcárate, pero en todas hay elementos de verdad como dijo, en el Congreso de la Religiones, de Chicago en 1893, un Arzobispo católico. A pesar de las diferencias religiosas, dijo el Arzobispo de Chicago, hay una "común humanidad, un sincero respeto y reverencia, un sentimiento cordial y fraternal de amistad". Y el cardenal Gibbons recuerda a todos el programa de la caridad, la humanidad y la benevolencia. San Agustín habla de la Iglesia desde Abel, y Tertuliano del alma "naturaliter cristiana". Boutroux, Spencer y Guyau, nos hablan de una religión del misterio que se liga con la ciencia ${ }^{63}$.

La Filosofía de la Religión estudia la religión en sí misma o la esencia de la religión. La religión es un problema metafísico, psicológico, sociológico, pragmático, y, según Taine, "un poema metafísico acompañado de creencia", eficaz y popular, que sabe llegar a todos. Produce la integración del hombre y beneficia a toda la humanidad para que no se destruya. Jaurés, el socialista francés, creía un error mortal abolir las creencias religiosas.

Para Séneca, la religión es conocer a Dios e imitarle. Para Kant, reconocer nuestros deberes como mandamientos divinos. Para Huxley, el amor al ideal ético y el deseo de realizarlo. Para Schleiermacher, el sentimiento y la intuición de lo Infinito. Para otros, la religión es todo lo mejor de la vida y, además, laborare est orare ${ }^{64}$. Los antiguos, paganos, llamaban ateo al que no aceptaba sus dioses, p. e. los Padres de la Iglesia. Haeckel decía no soy ni teísta ni ateo. Del mismo modo, para algunos, agnosticismo es irreligión para otros sentido del misterio. La religión nos une con el Absoluto, es oración y sentido comunitario, algo personalísimo e íntimo, por eso el Estado no puede "servirla sin ofenderla, ni protegerla sin profanarla", según decía el krausista liberal A. Calderón 65 .

Es más: "Contra viento y marea eclesiástica, existió una minoría de intelectuales católicos liberales y republicanos como Fernando de Castro, Francisco Giner de los Ríos, Gumersindo de Azcárate, Joan Maragall, Miguel de Unamuno o, más tarde, José Bergamín, impulsor de la revista Cruz y Raya, que constituye el proyecto más acabado de una intelectualidad católica republicana (Aranguren: 1998)"66.

63 Conferencia La Religión y las Religiones, MT 263.

64 La R. y las Rs. 276.

65 La R. y las Rs. 279.

66 DÍAZ-SALAZAR, R., El factor católico en la política española. Del nacionalcatolicismo al laicismo. PPC, Madrid 2006, 145. 
Hay cierta unidad del Fenómeno religioso y una variedad que muestra la Historia de la Religiones desde el arte prístino hasta el animismo y la filosofía griega. Azcárate cree que san Bernardo no valora este mundo y que está vertido al otro, pero el Renacimiento trae nuevos aires humanistas. Bacon y Descartes emancipan la Filosofía de la Teología, y así nace el Derecho y la Ética civil. Surge también la nueva ciencia y luego las Revoluciones, obra, también, de la Providencia divina, y para nada obra del diablo...

Es preciso reconciliar cristianismo y ciencia, y el cristianismo y la religión del pueblo como hace Vacherot. Se trata de la religión del Jesús de Nazaret, de su muerte y resurrección, de la religión de la caridad descrita por san Pablo en $1^{a}$ Cor. 13. Así, la Religión es tan permanente como la Ciencia, el Arte o el Derecho, y como ellas cambia y se modifica. Esa es la Religión que describía Concepción Arenal en Cartas a un Señor: La Religión es algo íntimo que arranca de lo profundo del corazón, es también comunión, es amor y justicia. Se trata de la religión de la vida, no de cumplir ciertos deberes religiosos, y de hacer todo el bien que se pueda hacer y evitar todo el mal que se pueda contra cualquier persona por insignificante que sea socialmente 67 .

El Obispo de León, D. Ramón, en carta del 21-1-1910, acusa recibo de esta Conferencia de Azcárate, le avisa de su racionalismo pero también le alaba sus "miras elevadas y nobilísimos sentimientos" y "ánimo sincero", y le manda sus respetos. Azcárate le contesta agradecido y asegurándole su interés por la religión misma, a la vez que le expresa su amistad. También hay aquí una carta de Antonio Maura a Azcárate en la que le señala la enorme distancia entre Azcárate y la "bullanga callejera" que habla de tolerancia y libre convivencia.

También el obispo de Salamanca en una carta, del 5-2-1910, le agradece su amistad. Le recuerda su racionalismo, frente a los dogmas y milagros, pero como se trata del "racionalista menos acatólico" que conoce, espera, como santa Mónica, su conversión plena. Le pide que se abra totalmente a la luz de lo alto, y ruega disculpe sus "atrevimientos con la bondad con que me dispensó siempre", y le expresa su "cariño sincero de su amigo y servidor que le bendice" 68 .

También, D. José, el nuevo obispo de León en 7-1-1914, le expresa a Azcárate su gratitud por la bondad con que ha acogido su Carta-Pastoral y le agradece el envío de la conferencia: La Religión y las Religiones. Le

${ }^{67}$ La R. y las Rs. 290.

${ }^{68} \mathrm{La}$ R. y las Rs. 296-7. 
parece que Azcárate tiene un sentimiento religioso parecido al de san Agustín y piensa que le falta algo. Y le dice: "Acaso hablando nos entendiéramos, y Dios quiera que así suceda". Y se despide con el ofrecimiento de "su mayor consideración" y amistad.

\section{Justino de Azcárate (1903-1989), Ortega y la Asociación al Servicio de la República}

J. de Azcárate fue Subsecretario del Ministerio de Justicia en el primer Gobierno de la República, y Diputado por León en las Constituyentes de 1931. Sabemos que se sentaba en el Parlamento junto a Ortega. Fue Secretario de la Agrupación al Servicio de la República fundada por Ortega, Ayala, Marañón y A. Machado. Como tal secretario firma la Circular, de la Agrupación al Servicio de la República, del 29 de enero de 1932, basada en ideas de José Ortega y Gasset, su Presidente.

En ella se habla de Nación y Trabajo, de un nuevo Estado, de un poder público que oriente toda la economía más allá de los intereses particularistas del patrono o del obrero aunque contando con todos, partiendo de la idea de que un grupo no puede imponerse a otro y todos tienen la obligación de crear riqueza y de repartirla adecuadamente, pues todos tienen el deber de trabajar, de hacer algo para hacerse personas. Así que el lema de esta Agrupación es: Nación y Trabajo, un proyecto común, de una "España magnífica", y un proyecto para todos. En ese sentido se requiere una economía nacional bajo un Consejo de Economía Nacional que marque las orientaciones fundamentales para toda la Nación.

Además, se pide una Reforma Agraria para que la tierra pase, sin atropellos, de manos parásitas a manos activas y expertas, y se acerque la tierra al obrero con una legislación social adecuada. También se trata de organizar la Vida local, no solamente en los ayuntamientos y provincias sino también con las Regiones y Autonomías como "miembros naturales de la Nación"69. Se pide, igualmente, renovar la Constitución a partir de acatar la que ya hay, pero intentando que adolezca menos de "esquematismo doctrinario" y consiga un mayor equilibrio más representativo y menos partidista.

También se trata la Cuestión religiosa para conseguir un estado laico que evitara toda "agresión a los grupos católicos de España" así como la persistencia de sus "privilegios políticos" antinacionales. Así, se evitarán

69 Ortega y Gaset, J., Circular, O. C. XI, Madrid 1983, 429. 
las guerras de religión que sólo son propias de Estados bárbaros. En cuanto a la Enseñanza, se ha de nacionalizar pero no por medio de leyes y coerciones externas a la enseñanza privada sino con una enseñanza pública mejor. La Sanidad pública es también una función del Estado y una gran riqueza nacional ${ }^{70}$.

"Al ser convocadas las elecciones de la Constitución de la República, don José recibió ofrecimientos de varios partidos para figurar como candidato en tres o cuatro provincias. Eligió León y ello me proporcionó la gran satisfacción de acompañarle en la breve pero intensa campaña y sobre todo de salir juntos elegidos diputados"71.

Ortega participa en un mitin, el 19-6-1931, en la Plaza de Toros de León, de la Conjunción republicano-socialista de cuya candidatura formaba parte el autor ${ }^{72}$. El texto de esta intervención sólo existe en los resúmenes de la prensa. Así, Ortega y Gasset, fue Diputado por León.

Además Ortega da una Conferencia en el Teatro Principal de León el 26.6.1931. Ortega afirma en ella que hay que tener ideas claras sobre el Estado y que no hay que tratar a la gente como borrachos enviándolos como ovejas a las urnas o como búfalos a la revolución ${ }^{73}$. Es necesario superar las vanas promesas y hablar a la gente con claridad sin caer en la demagogia que perjudica a la República y la hace poco creíble. Pide electores con mente serena y clara que no se dejen embriagar con vanos discursos. "Yo no quiero hacer política con borrachos; todo lo contrario, necesito apelar al fondo claro, luminoso, de la conciencia de cada uno de vosotros"74.

Ortega señala, aquí, "la novísima democracia leonesa", consciente de sí misma, de plena actualidad, "con rumbo fijo, sin romper los grupos, sin diferencias, comportándose con energía y seriedad", un ejemplo para el resto de la Península que verá "en la democracia leonesa una política y un modelo a seguir".

Ahora bien, primero, hay que hacer un Estado nuevo, que a partir de las finalidades adecuadas, tenga las piezas necesarias para atacar los problemas que nos preocupan. No se pueden traer esquemas de fuera sin más, como los de la Revolución francesa y su Estado centralista, porque Francia es una Nación homogénea pero España no es así. Su clima y sus

70 Ortega y Gaset, J., Circular, 430.

71 AZCÁrate, J., Sobre la actividad política de Ortega, Revista de Occidente 24/25, 1983, 27.

72 ORTEGA Y GaSET, J., Discurso en León, O. C. IX, 307. En adelante DL.

73 DL 301.

${ }^{74} D L 302$. 
tierras son muy variadas y cada comarca y cada lugar tiene sus plantas y su estilo. Entonces, desde Madrid no se puede atender a todo. Y así, en las Provincias surgió el descontento contra el Estado centralizado y ajeno a la vitalidad provincial. Hay que poner las Provincias en pie como se explica en la La España Invertebrada y La Redención de las Provincias.

Por tanto, hay que organizar las Comarca, y las Autonomías para enfrentarse a los problemas concretos con garantía de éxito y con una cierta fuerza de población frente a la dificultad del paisaje y del subsuelo. Así, las Asambleas Regionales y los Gobiernos locales potenciarán nuestras posibilidades con toda su capacidad. Y, se espumarían también los políticos para la vida Nacional donde llegarían los mejores hombres con todo su dinamismo.

Pero hay otras cosas importantes que configuran todo lo demás. La primera y más importante es el horizonte actual de nuestra vida nacional e internacional. Se trata de "la sociedad organizada en pueblos de trabajadores" que ya no puede ni debe "asustar a nadie"75. En este sentido, hoy todas las naciones son socialistas porque todos dependemos de todos, en cada nación y en todo el mundo. Así la organización de la sociedad en "pueblos de trabajadores" no es un problema económico, ni de capitalismo o socialismo, es un problema moral. La sociedad no puede valorar a quien no se ocupa de nada, al que vive sin trabajar, porque esfuma su energía íntima, desprecia sus dotes, talentos y capacidad. Esa fue la tragedia de las aristocracias del pasado que sestearon en el ocio y arruinaron su vida.

El hombre europeo ha descubierto que el trabajo, intelectual o manual, hace al hombre más auténtico, y afirma a su personalidad fácil a descomponerse. Cada ciudadano es, pues, un trabajador, también el capitalista que crea riqueza. Se trata de que cada cual cumpla con la obligación humana de hacer algo. Pero, además, hay que tratar de que "todo hombre pueda seguir su vocación, porque esto es salvar su vida"76. Hay que hacer un Estatuto General del Trabajo, "sin prisa pero sin pausa" como decía Goethe que marchan las estrellas. Eso llevará a la "sindicación firme de todos los españoles" en un proyecto común.

Todo este proceso conseguirá, para todos nosotros, una gran transformación socio-económica. Pero los viejos revolucionarios españoles seguirán con sus consejas algo anticuadas. No se dan cuenta que para la reforma social del mundo de nada sirven la revoluciones cruentas. Porque

75 DL 307.

${ }^{76} D L 309$. 
nada puede cambiar la vida del obrero y la estructura económica, "si no aumenta en grandes proporciones la riqueza pública". Hay que cambiar la acción directa por el entusiasmo de la creación industrial. Sólo así es posible la socialización de la riqueza.

Por eso, hay que concebir la Nación como una gran empresa común, sin aplastar ni al trabajador productor ni al empresario. Debe haber una Junta Nacional de Economía que fije las grandes líneas de la reforma general. Sólo así puede modificarse radicalmente el tejido económico de España. Hoy la revolución incendiaria está agotada y la verdadera revolución es la revolución de la técnica, de la construcción económica y "el orden fecundo de la sociedad organizada en cuerpo de trabajadores". Para eso pide Ortega su concurso a los leoneses: para "hacer una España magnífica, ya que esta comarca ha revelado siempre un claro sentido para toda alta empresa de historia"77.

Por lo demás, Justino de Azcárate fue nombrado Ministro de Estado el 17-7-1936, pero no llegó a tomar posesión. Detenido en la cárcel de Valladolid, fue condenado a muerte. Indultado, fue exiliado en Venezuela muchos años. Senador por designación Real en 1977, fue, de nuevo, Parlamentario por León en 197978. Y así, ha podido escribir esta preciosa memoria de su relación personal y política con Ortega.

\subsection{Manuel Azcárate}

Manuel es hijo de Pablo de Azcárate, hijo de Cayo, hermano de Gumersindo. Según su propia experiencia, para Manuel Azcárate, ser de la ILE significaba:

1. Respetar a las otras personas por modestas que fuesen,

2. Mantener una conducta moral intachable basada en la tolerancia y la equidad,

3. Decir siempre la verdad y

4. Hacer con seriedad el propio trabajo ${ }^{79}$.

${ }^{77}$ DL 311.

78 Gran Enciclopedia de Castilla y León, Edical S.A., Valladolid 2003, 77.

79 NATAL, A., Manuel Azcárate y Eugenio de Nora, en M. Fartos, L. VelázQuez, T. PAstor, La Filosofía Española en Castilla y León, Universidad de Valladolid 2000, 614. 
Conoce a García Lorca a través de Fernando de los Ríos. Trabaja en la Embajada española en París para mantener el contacto con el Presidente francés León Blum. Se encuentra con Miguel Hernández en Teruel. Su familia mantiene también una buena relación con Negrín, a quien reivindica. Negrín era médico, diputado socialista en todas las legislaturas, hablaba varios idiomas, y el único español que seguía el debate que había en Europa, según M. Azcárate.

En la Resistencia francesa trabaja con el nombre de "Jaime". Al fin de la guerra, M. Azcárate intenta poner en contacto a Dolores Ibárruri con Negrín. Pablo Picasso que había ingresado en el PCF, preside el Comité de ayuda a los refugiados, y lo hace con la indicación de que M. Azcárate sea el Secretario. S. Carrillo le pone en contacto con E. de Nora como puede verse en el citado artículo al que remitimos para todo lo demás. Azcárate fue dirigente del PCE durante mucho tiempo. Y finalmente, fue expulsado del partido por militar en el sector renovador.

\subsection{Los otros Azcárate}

Otros Azcárate notables por su relieve intelectual, político o social cercanos al de Patricio, Gumersindo, Justino o Manuel Azcárate, fueron:

D. Tomás Azcárate Menéndez. Profesor de Matemáticas aplicadas y director del Observatorio Astronómico. Ayudó a Isaac Peral a inventar el Nautilus, el primer submarino conocido.

D. Pablo Azcárate. Subsecretario de la Sociedad de Naciones, actualmente la ONU. Primer Alcalde de Jerusalén bajo administración de la ONU.

D. Tomás Azcárate G. de la Loma. Hombre de la Marina española. Se negó a seguir a los sublevados de Cádiz en 1936. Y, por eso, fue fusilado.

D. José María Azcárate Ristori. Catedrático de $\mathrm{H}^{\mathrm{a}}$. del Arte en la Univ. Complutense de Madrid. Sus apuntes fueron famosos entre los estudiantes de Arte de toda España. 
Dña. Isabel Azcárate Ristori. Fue una gran Pedadoga, en la vanguardia de las mujeres de la nueva educación española de la ILE.

D. Luis Azcárate. Director de la Escuela Social de Madrid, fundada por Gumersindo de Azcárate, ahora integrada en la Universidad Complutense 80 .

\author{
Domingo Natal Álvarez, \\ Villimer (León): Casa de los Azcárate \\ y Estudio Agustiniano de Valladolid
}

80 Otros miembros de la familia son: Juan, Tito y Marina. D. Juan C. Entrecanales de Azcárate, es el actual cabeza de familia. Gran empresario, al que debemos algunas de estas informaciones. Su hijo José Manuel y el primo de éste, Juan Ignacio, ocupan puestos directivos decisivos al frente de empresas de gran calado nacional e internacional como hoy son Acciona y Vodafone. 